\title{
Isolation and characterization of Aphanocladium album chitinase-overproducing mutants
}

\author{
Valerie Vasseur, ${ }^{1 *}$ Fabrizio ARIgoni, ${ }^{1}$ Hedwig Andersen, ${ }^{2}$ Genevieve Defago, ${ }^{2}$ \\ GILBERT BOMPEIX ${ }^{1}$ and JEAN-MARC SENG ${ }^{1}$ \\ ${ }^{1}$ Université Pierre et Marie Curie, Laboratoire de Biochimie et Pathologie Végétales, Tour 53, 4 Place Jussieu, \\ 75252 Paris Cedex 05, France \\ ${ }^{2}$ Institute of Phytomedicine, Swiss Federal Institute of Technology, CH-8092 Zürich, Switzerland
}

(Received 14 June 1990; revised 24 August 1990; accepted 7 September 1990)

\begin{abstract}
A wild-type strain of the fungus Aphanocladium album was mutagenized by $\mathrm{UV}$ irradiation in order to obtain chitinase-overproducing mutants. Mutants were screened on agar medium containing colloidal chitin and selected for their ability to produce large clearing zones around the colonies. Two mutant strains, designated E3 and E12, showed respectively a 26- and a 2.5-fold increase in maximal extracellular chitinase activity, determined in liquid medium with crystalline chitin as sole carbon source, compared to the wild-type strain. This is believed to be the first report on the induction of stable chitinase-overproducing mutants in a filamentous fungus. Regulation of enzyme activity was investigated in mutant $\mathrm{E3}$ and the wild-type strain.
\end{abstract}

\section{Introduction}

Chitin, an unbranched polysaccharide composed primarily of $\beta$-1 $\rightarrow 4$-linked $N$-acetyl-D-glucosamine residues, is hydrolysed to $N$-acetyl-D-glucosamine (GlcNAc) by two separate hydrolases : an endochitinase (EC 3.2.1.14) which produces soluble low-molecular-mass multimers of GlcNAc, the dimer $N, N^{\prime}$-diacetylchitobiose being predominant, and chitobiase (EC 3.2.1.30), which hydrolyses the intermediates to GlcNAc. In the literature both enzymes are often grouped under the name chitinase (Jeuniaux, 1963; Monreal \& Reese, 1969; Reid \& Ogrydziak, 1981). Chitinases have been detected in a variety of organisms: bacteria, fungi, plants, insects and vertebrates (for reviews see Boller, 1986; Gooday, 1986). These enzymes are known to perform several biological functions: together with chitin synthases (EC 2.4.1.16) they are required for the morphogenesis of fungal and arthropod cell walls. They may play a nutritional role in the case of soil saprophytes such as Aspergillus (Monreal \& Reese, 1969) and Trichoderma. In the case of pathogens of crustacea, insects and fungi, chitinase production allows them to penetrate their hosts. Moreover, these enzymes are produced in large quantities by actinomycetes and streptomycetes and presumably contribute to soil antibiosis (Sneh, 1981). Plant chitinase is

Abbreviation: GlcNAc, $N$-acetyl-D-glucosamine. involved in defence reactions against fungal pathogens, either through a direct inhibitory effect (cell wall lysis) (Schlumbaum et al., 1986; Roberts \& Selitrennikoff, 1988), or via an indirect effect (release of fungal cell wall elicitors) (Keen \& Yoshikawa, 1983; Hadwiger et al., 1986). During the last decade, chitinases have received increasing attention due to their potentially wide range of applications (Cosio et al., 1982; Jones et al., 1986). One use of chitinase is the digestion of the chitin component of many agronomic pests, including insects, fungi and nematodes. The enzyme could be used directly in biological control via a micro-organism (Ordentlich et $a l ., 1987)$ or indirectly, using the purified protein or the gene encoding the chitinase (introduction of chitinase gene into plants or bacteria) (Lund et al., 1989; Shapira et al., 1989).

A survey of micro-organisms able to degrade crystalline chitin (native form) showed that the bacteria Serratia marcescens and Enterobacter liquefaciens produced almost 10-fold more chitinase than the second-best producer, the fungus Aspergillus fumigatus (Monreal \& Reese, 1969). S. marcescens and other bacteria such as Vibrio vulnificus and $V$. harveyi appeared to be very promising tools for the production of large amounts of chitinase (Soto-Gil \& Zyskind, 1984; Fuchs et al., 1986; Wortman et al., 1986). Different studies have since been initiated on Serratia marcescens with subsequent genetic and biochemical investigations carried out in order to 
better characterize chitinase and to optimize the level of enzyme production (Tom \& Carroad, 1981; Roberts \& Cabib, 1982; Young et al., 1985a,b). Reid \& Ogrydziak (1981) reported the isolation of chitinase-overproducing mutants of $S$. marcescens, but the mutants were unstable, presumably because the mutation was a tandem gene duplication.

Fungi have so far received little attention in this field. A study by Srivastava et al. (1985) revealed that the deuteromycete fungus Aphanocladium album produced high levels of extracellular chitinase when grown in minimal medium with crystalline chitin as sole carbon source. A preliminary study in our laboratory (unpublished data) showed that $A$. album grew better on chitin agar medium than did several entomopathogenic fungi such as Beauveria bassiana, B. tenella, Metarhizium anisopliae and Verticillium lecanii, which are known to be chitinase producers (Smith \& Grula, 1983; Coudron et al., 1984; St Leger et al., 1986).

Here we report the isolation of stable chitinaseoverproducing mutants of Aphanocladium album after one-step UV mutagenesis, showing extensive clearing of chitin on agar plates. Two mutants, E3 and E12, were compared to the wild-type strain for their chitinase production in submerged culture. The mechanisms of regulation of chitinase activity were investigated in mutant E3 and the wild-type strain. The possible mechanism(s) of chitinase overproduction by mutant E3 are discussed.

\section{Methods}

Strain and culture maintenance. The wild-type strain of Aphanocladium album, ETH M483 (referred to as E1 in this study), was provided by the Institute of Phytomedicine, ETH-Zürich, and maintained at $25{ }^{\circ} \mathrm{C}$ on cristomalt medium, consisting of $1 \%(\mathrm{w} / \mathrm{v})$ cristomalt (Difal, France) and $1.7 \%$ (w/v) Bacto Agar (Difco).

Preparation of colloidal chitin. A modification of the method described by Skujins et al. (1965) was used. Thirty grams of crystalline chitin (Fluka) were mixed with $250 \mathrm{ml} 10 \mathrm{M}-\mathrm{HCl}$ and left for $4 \mathrm{~h}$ at room temperature, then 5 litres of distilled water were added. After chitin precipitation, the water was removed and 5 litres of fresh distilled water were added. The precipitate was removed by centrifugation and rinsed several times with water until the $\mathrm{pH}$ was neutral. The colloidal chitin was then lyophilized.

Mutagenesis. Mycelia-free spore suspensions were subjected to UV irradiation for various time intervals corresponding to different survival rates. Aliquots of $0.1 \mathrm{ml}$ were then plated on colloidal chitin agar, consisting of $1 \%(\mathrm{w} / \mathrm{v})$ colloidal chitin and $2 \%(\mathrm{w} / \mathrm{v})$ agar, to give approximately 50 viable colonies per plate, as previously established from dose-response curves.

Plate screening methodology. After mutagenesis, plates were incubated at $24^{\circ} \mathrm{C}$ and observed periodically for colony growth and for visible clearing of chitin around the colonies. Isolated colonies showing either a larger clearing zone or a better growth rate than the wild-type strain were subcultured on cristomalt medium and tested again on the screening medium after being cloned.
Culture conditions. Cultures were grown in $250 \mathrm{ml}$ Erlenmeyer flasks containing a $1 \%(\mathrm{w} / \mathrm{v})$ carbon source, which was either D-glucose (Prolabo, France), L-malic acid (Sigma), crystalline chitin or $\mathrm{N}$-acetylD-glucosamine (GlcNAc) (Sigma) in $50 \mathrm{ml}$ of modified medium of Srivastava et al. (1985), containing: $8.25 \mathrm{~g}\left(\mathrm{NH}_{4}\right)_{2} \mathrm{SO}_{4} ; 0.5 \mathrm{~g}$ $\mathrm{MgSO}_{4} .7 \mathrm{H}_{2} \mathrm{O} ; 2.5 \mathrm{~g} \quad \mathrm{KH}_{2} \mathrm{PO}_{4} ; 0.06 \mathrm{~g} \quad \mathrm{FeCl}_{3} .6 \mathrm{H}_{2} \mathrm{O} ; 0.01 \mathrm{~g}$ $\mathrm{ZnSO}_{4} .7 \mathrm{H}_{2} \mathrm{O} ; 1.6 \mathrm{~g} \mathrm{MnSO}_{4} . \mathrm{H}_{2} \mathrm{O}$ per litre distilled water. The $\mathrm{pH}$ of the medium was adjusted to 5.0 prior to autoclaving. Media containing L-malic acid and D-glucose were buffered with $0.2 \mathrm{M}-2-(N$-morpholino)ethanesulphonic acid (Sigma). The chitin was ground in a cylinder mill (Schleicher \& Schüll) and then sifted in order to obtain a particle fraction with a diameter of $44-125 \mu \mathrm{m}$. Flasks were shaken for different time intervals on a rotary incubator $\left(80\right.$ r.p.m.) at $24^{\circ} \mathrm{C}$.

Diffusion capsules. Diffusion capsules consisted of cylindrical containers $(2.5 \mathrm{ml})$, filled with a solution of GlcNAc. Rates of monomer diffusion were controlled by altering the concentration of solute inside the capsules and the number of membranes through which diffusion occurred. Capsules containing a solution of $5 \%(w / v)$ GlcNAc and sealed with one semi-permeable membrane, i.e. a cellulose dialysis tube with a molecular mass cut-off of $10000 \mathrm{Da}$, gave linear diffusion rates of about $30 \mu \mathrm{g} \mathrm{ml}^{-1} \mathrm{~h}^{-1}$ over $17 \mathrm{~h}$. Capsules were replaced twice a day to ensure linear release.

Sterilization. Culture media were sterilized by autoclaving at $121^{\circ} \mathrm{C}$ for $30 \mathrm{~min}$. D-Glucose and GlcNAc were sterilized by membrane filtration (Millex-GS $0.22 \mu \mathrm{m}$, Millipore) under reduced pressure and incorporated in autoclaved media. Diffusion capsules were autoclaved for $30 \mathrm{~min}$ at $121^{\circ} \mathrm{C}$ and filled with the sterile monomer solution. Dialysis membrane and empty capsules were washed with ethanol, rinsed with sterile water and immersed in the medium.

Inoculum. Chitin medium was inoculated with conidia taken from a 5-d-old cristomalt culture $\left(2 \times 10^{6}\right.$ conidia per $50 \mathrm{ml}$ medium $)$. In the other experiments, a standardized inoculum was prepared from $60 \mathrm{~h}$

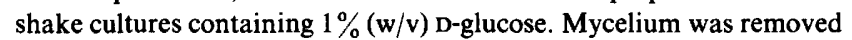
by sterile filtration, washed with sterile water and transferred to the following media: GlcNAc capsule, $1 \%(w / v)$ GlcNAc, $1 \%(w / v)$ Dglucose or $1 \%(\mathrm{w} / \mathrm{v})$ L-malic acid. The biomass of fungus grown on soluble carbon sources was estimated by measurement of the dry weight. The mycelium was dried for $24 \mathrm{~h}$ at $70^{\circ} \mathrm{C}$ and then weighed. When the fungus was grown on chitin (insoluble polymer), the dry weight could not be estimated because of the strong adsorption of chitin to the mycelium.

Enzyme production. After several hours, cultures were filtered through Whatman no. 1 filter paper and rinsed with $0 \cdot 2 \mathrm{M}$-sodium

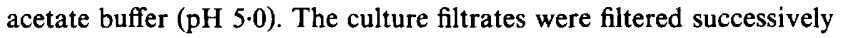
through 8,3 and $0.2 \mu \mathrm{m}$ cellulose nitrate filters (Sartorius). Filtrates were analysed for GlcNAc, D-glucose or L-malic acid content. They were assayed for chitinase activity after dialysis (molecular mass cut-off of cellulose dialysis tube: $10000 \mathrm{Da}$ ) against stirred distilled water with the final bath against $0 \cdot 2 \mathrm{M}$-sodium acetate buffer ( $\mathrm{pH} 5 \cdot 0$ ).

Concentration of crude extracts. When cultures were grown on D-glucose or L-malic acid, the crude extracts were concentrated with polyethylene glycol (20000 Da exclusion limit) and then dialysed against $0 \cdot 2 \mathrm{M}$-sodium acetate buffer ( $\mathrm{pH} 5 \cdot 0)$.

Titration of L-malic acid. L-Malic acid was measured enzymically with a test kit (Boehringer Mannheim).

Titration of D-glucose and GlcNAc. D-Glucose was measured by the modified method of Nelson (1944). Somogyi's reagent $(0.2 \mathrm{ml})$ was added to $0.2 \mathrm{ml}$ of the sample. The tubes were heated at $100{ }^{\circ} \mathrm{C}$ for $45 \mathrm{~min}$. After cooling in ice, $0.2 \mathrm{ml}$ Nelson's reagent and $4.4 \mathrm{ml}$ distilled water were added successively. Absorbance was read at $500 \mathrm{~nm}$.

GlcNAc was measured by the method of Reissig et al. (1955). 
Chitinase activity. Dialysed filtrate $(1 \mathrm{ml})$ was incubated for $30 \mathrm{~min}$ at $37^{\circ} \mathrm{C}$ with $0.5 \mathrm{ml}$ of a $2 \%(\mathrm{w} / \mathrm{v})$ reacetylated crystalline chitin (Molano et al., 1977) suspended in $0.2 \mathrm{M}$-sodium acetate buffer (pH 5.0). After centrifugation, GlcNAc was measured in the supernatant by the method of Reissig et al. (1955). One unit (U) of chitinase activity was defined as the amount of enzyme that catalysed the release of $1 \mu \mathrm{mol}$ GlcNAc $\mathrm{ml}^{-1}$ in $30 \mathrm{~min}$.

\section{Results}

\section{Isolation and characterization of the mutants}

When spores of the wild-type strain, E1, were plated on colloidal chitin agar medium, they developed a relatively dense mycelium without any visible clearing zone around the colony. Approximately 10000 colonies were examined after mutagenesis on this screening medium. Two of them showed an extensive clearing zone around the colony between days 4 and 8 of incubation and were designated E3 and E12 respectively. Both were recovered at a UV dose corresponding to $10 \%$ survival. When grown on chitin agar medium, the two mutants exhibited a similar radial growth rate but with considerably narrower hyphae than the wild-type strain. This particular morphology was not due to auxotrophy, because all the strains displayed a dense mycelial morphology on the same medium when glucose was used as the sole carbon source. Several colonies with altered growth patterns were also recovered. Those with an increased radial growth on colloidal chitin were selected but when cultivated in liquid medium they did not show higher chitinase activity than the wild-type strain.

\section{Stability of the mutants}

The stability of E3 and E12 was tested by successive monoconidial subcultures on cristomalt medium. After five subcultures in the absence of chitin, the mutants were still able to develop a large clearing zone on colloidal chitin. The two mutants were cloned each month and always displayed the ability to develop a clearing zone on colloidal chitin.

\section{Chitinase production in shake flasks}

Mutants E3 and E12 showed markedly higher chitinase activity than the wild-type strain E1 cultured under similar conditions (Table 1). Maximum activities of E3 and E12 were observed after $20 \mathrm{~d}$ of culture, and were 26and $2 \cdot 5$-fold higher, respectively, than the maximum reached by strain E1 on day 10. Mutant E3 showed the highest chitinase activity throughout the culture.

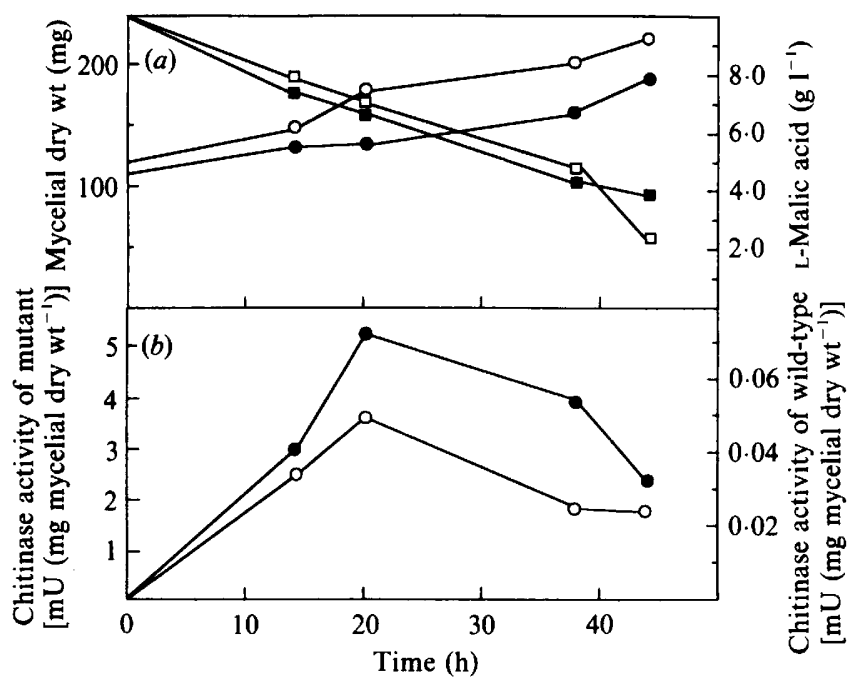

Fig. 1. (a) Mycelial growth $(O, \bigcirc)$ and L-malic acid content $(\square, \square)$,

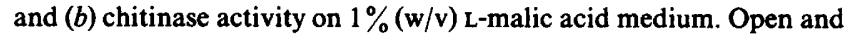
filled symbols represent, respectively, data for the wild-type strain E1 and for the mutant E3. Values are means of three independent assays.

Table 1. Production of chitinase by A. album grown in shake flasks on $1 \%$ chitin medium

\begin{tabular}{cccc}
\hline \hline \multirow{2}{*}{$\begin{array}{c}\text { Incubation } \\
\text { time } \\
\text { (d) }\end{array}$} & \multicolumn{3}{c}{ Chitinase activity $\left(\mathrm{mU} \mathrm{ml}^{-1}\right)^{*}$} \\
\cline { 2 - 4 } & Wild-type E1 & Mutant E3 & Mutant E12 \\
\hline 5 & $10 \cdot 7$ & $72 \cdot 0$ & $52 \cdot 5$ \\
10 & 108.0 & $600 \cdot 0$ & $178 \cdot 8$ \\
15 & $51 \cdot 8$ & $1992 \cdot 0$ & $182 \cdot 4$ \\
20 & 33.6 & 2868.0 & $268 \cdot 8$ \\
30 & 12.6 & 145.6 & $30 \cdot 4$ \\
\hline \hline
\end{tabular}

* One unit (U) of chitinase activity was defined as the amount of enzyme that catalysed the release of $1 \mu \mathrm{mol} \mathrm{GlcNAc} \mathrm{ml}^{-1}$ in $30 \mathrm{~min}$.

\section{Constitutive level of chitinase activity}

We attempted to find a carbon source which induces no catabolic repression: Krebs cycle intermediates are generally used for this purpose because they are less rapidly utilized than glucose and should therefore cause less repression. The effect of L-malic acid on growth and chitinase activity was tested. In $1 \%$ (w/v) L-malic acid medium, the increase in biomass after $44 \mathrm{~h}$ of culture was $107 \mathrm{mg}$ dry weight for $\mathrm{E} 1$ and $60 \mathrm{mg}$ dry weight for E3 (Fig. 1a). The concentration of L-malic acid in the medium remained very high for both strains up to $20 \mathrm{~h}$ of culture $\left(7 \cdot 14 \mathrm{~g} \mathrm{l}^{-1}\right.$ for $\mathrm{E} 1$ and $6.98 \mathrm{~g}^{-1}$ for $\left.\mathrm{E} 3\right)$; in the medium after $44 \mathrm{~h}$ of culture, however, there remained $23 \%$ of the initial concentration with $\mathrm{E} 1$ and $40 \%$ with E3 (Fig. 1a). The two strains displayed a constitutive 


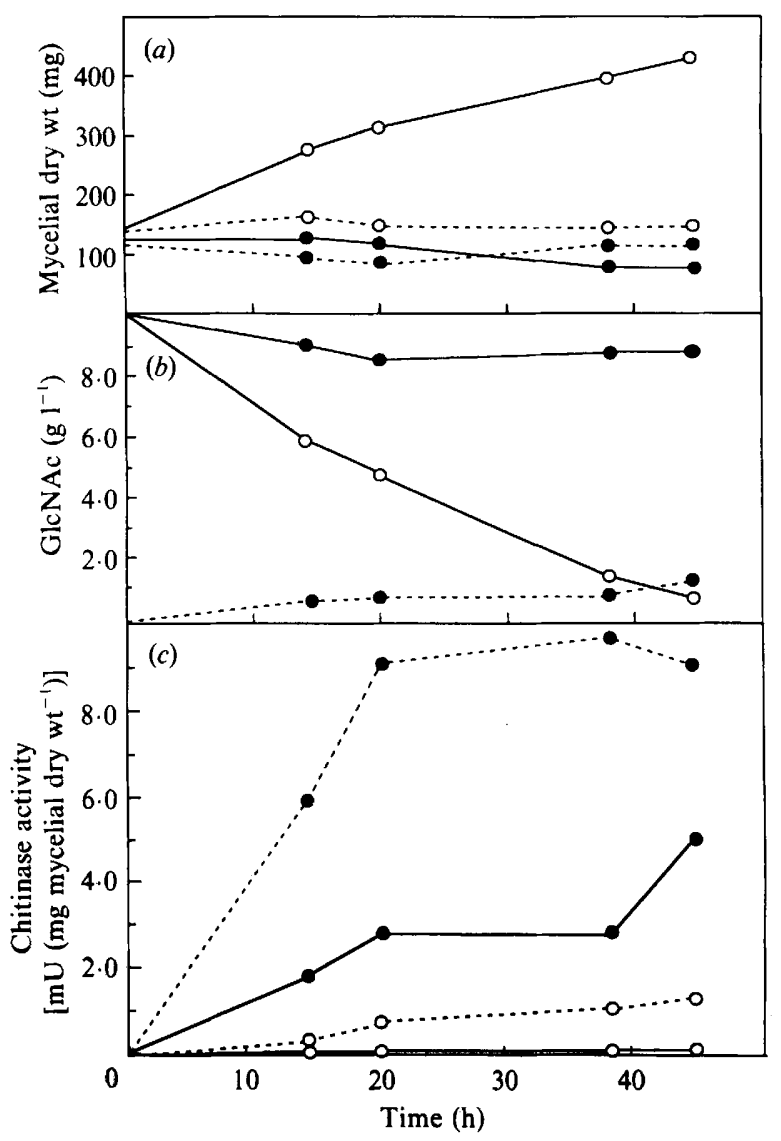

Fig. 2. (a) Mycelial growth, (b) GlcNAc content and (c) chitinase activity on $1 \%(w / v)$ GlcNAc medium (solid lines) and on GlcNAc capsule medium (broken lines). Open and filled symbols represent, respectively, data for the wild-type strain E1 and for the mutant E3. Values are means of three independent assays.

level of chitinase activity which followed the same accumulation pattern (Fig. $1 b$ ), increasing up to $20 \mathrm{~h}$, then decreasing to about $50 \%$ of the maximum activity. Different hypotheses may be put forward to explain this phenomenon, e.g. destruction or inactivation of chitinase by proteases secreted by this fungus (see Manning \& Wood, 1983). Chitinase activity in the mutant strain E3 was on average 100 -fold higher than that measured in the wild-type strain E1.

\section{Induction and repression of chitinase activity by GlcNAc}

When diffusion capsules were used, growth of the wildtype strain E1 was considerably lower than in the $1 \%$ (w/v) GlcNAc medium (Fig. $2 a$ ). Growth was limited by the restricted rate of diffusion of the monomer through the capsule (feed limitation condition). No GlcNAc accumulation was observed throughout the culture of E1 in diffusion capsule conditions. In the $1 \%(\mathrm{w} / \mathrm{v})$ GlcNAc medium, the concentration of monomer decreased throughout the culture period and fell to about $4.6 \%$ of the initial concentration after $44 \mathrm{~h}$ (Fig. 2b). Poor growth of the mutant strain E3 and accumulation of GlcNAc were observed on media containing the monomer independent of conditions: GlcNAc capsule or $1 \%(\mathrm{w} / \mathrm{v})$ GlcNAc (Fig. $2 a, b)$. In the GlcNAc capsule

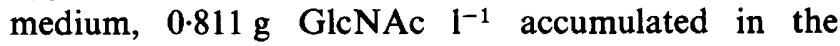
medium after $44 \mathrm{~h}$ of culture. Theoretically, the final concentration expected if no GlcNAc was taken up by the fungus would be $1.3 \mathrm{~g} \mathrm{l}^{-1}$. Thus nearly $38 \%$ of the GlcNAc accumulated was taken up by mutant E3. In the $1 \%(w / v)$ GlcNAc medium the concentration of GlcNAc remained very high - on average $8.9 \mathrm{~g} \mathrm{l}^{-1}$ - throughout all the culture; only $11 \%$ of the initial concentration had disappeared after $44 \mathrm{~h}$.

In GlcNAc capsule and in $1 \%(w / v)$ GlcNAc conditions, the viability of both strains was checked by testing the ability of a small mycelial sample to grow on cristomalt agar. After 4-5 d, both strains displayed good growth comparable to untreated mycelium.

Chitinase activity of both strains was consistently higher in the GlcNAc capsule than in the $1 \%(w / v)$ GlcNAc medium. Chitinase activity of the mutant was always higher (on average 10-fold higher) than that of the wild-type strain, independent of conditions (Fig. 2c).

The results showed that GlcNAc at a concentration of $1 \%$ could repress chitinase activity in both strains: in the wild-type strain, there was a strong correlation between the concentration of GlcNAc in the medium and the repressor effect of the monomer on chitinase activity. The mutant strain had a high level of chitinase activity although GlcNAc concentration remained high in the medium $\left(8.9 \mathrm{~g} \mathrm{l}^{-1}\right)$. An estimation was made of a 'repression ratio', the ratio between chitinase activity detected in GlcNAc capsule medium and chitinase activity measured in $1 \%(\mathrm{w} / \mathrm{v})$ GlcNAc medium. At $14 \mathrm{~h}$, this ratio was 24 in the wild-type strain and 3.5 in the mutant. The repressor effect of GlcNAc is thus more significant in the wild-type than in the mutant strain.

In both strains, chitinase activity was higher in GlcNAc capsule than in 1\% L-malic acid medium (Figs $1 b$ and $2 c$ ). A low concentration of monomer in the medium could also increase the basal level of chitinase activity. At $14 \mathrm{~h}$, the ratio between chitinase activity in GlcNAc capsule medium and that in $1 \%(\mathrm{w} / \mathrm{v}) \mathrm{L}$-malic acid medium was 10 in strain E1 and 2 in mutant E3.

\section{'Glucose effect' on chitinase activity}

As shown in Fig. 3(a), the growth of E1 and E3 in glucose medium increased rapidly up to $38 \mathrm{~h}$ and reached maximum values at $44 \mathrm{~h}$ (393 $\mathrm{mg}$ dry weight for $\mathrm{E} 1$ and $400 \mathrm{mg}$ for E3): at this time, the glucose was almost exhausted. Glucose is a carbon source which is easily and 


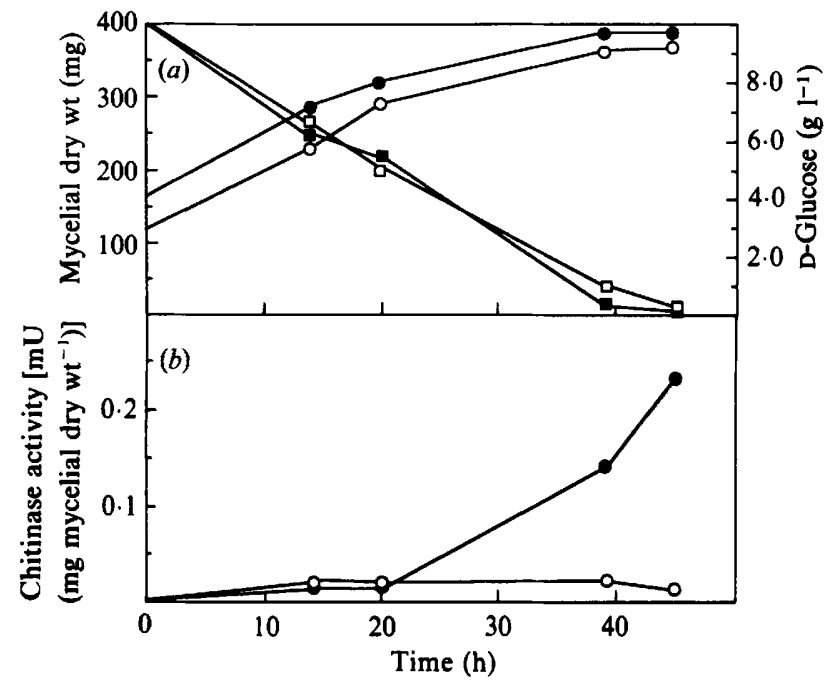

Fig. 3. (a) Mycelial growth $(O, \odot)$ and D-glucose content $(\square, \boldsymbol{\square})$, and (b) chitinase activity on $1 \%(\mathrm{w} / \mathrm{v}) \mathrm{D}$-glucose medium. Open and filled symbols represent, respectively, data for the wild-type strain $\mathrm{E} 1$ and for the mutant strain E3. Values are means of three independent assays.

rapidly assimilated by both strains compared to L-malic acid (Figs $1 a$ and $3 a$ ).

As shown in Fig. 3(b), the two strains displayed the same low level of chitinase activity during the first $20 \mathrm{~h}$ of culture; at the same time, the concentration of glucose in the medium was high $\left(5 \mathrm{~g}^{-1}\right)$. Chitinase activity of strain $\mathrm{E} 1$ remained very low throughout the culture. In contrast, chitinase activity of mutant E3 increased after $20 \mathrm{~h}$ of culture.

These results demonstrate that chitinase activity in both strains is repressed by glucose during early stages of growth, i.e., when glucose concentration in the medium is high. It is a well-known phenomenon in microorganisms that glucose is an easily assimilable carbon source which enters the glycolytic pathway directly. This is a self-regulating process whereby cells avoid wastage of resources and energy in synthesizing unnecessary enzymes. In our case, chitinase activity is not necessary in the presence of another rapidly utilizable carbon source. In the mutant strain, chitinase activity was repressed during $20 \mathrm{~h}$ of culture, and was derepressed after glucose had reached a low concentration in the medium. The constitutive level of chitinase activity was then detected.

\section{Discussion}

To our knowledge, this is the first report of chitinaseoverproducing mutants in a filamentous fungus. The selection of colonies forming clearing zones on colloidal chitin agar constitutes a qualitative screening method, which allows rapid examination of a large number of colonies after mutagenesis. We suggest that this method could be employed in other fungi known as chitinase producers to induce chitinase-overproducing mutants.

Chitinase production of mutants E3 and E12 and the wild-type strain was compared quantitatively in liquid culture. E3 and E12 exhibited greater chitinase activities than the wild-type strain. Chitinase activity was increased 26-fold in mutant E3: the increase was very high compared with that in overproducing mutants of Serratia marcescens (Reid \& Ogrydziak, 1981), which produced about two- to threefold as much chitinase activity as the wild-type strain.

The possible mechanism(s) responsible for the overproduction of chitinase in the E3 mutant was investigated.

The morphological aspect and growth rate of strains E3 and E1 were compared in various liquid media. In $1 \%$

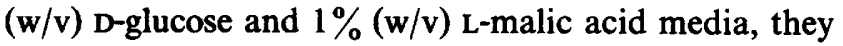
were nearly identical. On $1 \%(w / v)$ chitin medium, the strains displayed apparently the same growth, but it was impossible to estimate dry weight accurately because of the strong adsorption of chitin to the mycelium. Moreover, an increase in chitinase activity in E3 was not correlated with an increase in biomass. These results indicate that E3 is not a morphological mutant.

The regulation of chitinase activity in strains E3 and E1 was also compared. There are few reports on the regulation of chitinase activity in filamentous fungi. Smith \& Grula (1984) showed that the chitinase activity of Beauveria bassiana was inducible by GlcNAc, glucosamine or chitobiose. St Leger et al. (1986) demonstrated that chitinase activity in the entomopathogenic fungus Metarhizium anisopliae was regulated by products of chitin degradation through an inducer-repressor mechanism. The latter authors used, as we have done, a capsule diffusion test (Pirt, 1971) to demonstrate the induction of chitinase activity by GIcNAc. The use of these capsules prevents catabolite repression; micro-organisms use the solute at the rate of diffusion, which can be modulated and controlled according to the concentration of the substrate in the capsule and the number of membranes through which diffusion occurred. If, as in the present study, the capsules are changed regularly, before diffusion ceases to be linear, this system simulates a continuous culture. It is a very convenient method which has seldom been used in physiological studies on filamentous fungi.

Chitinase activity in both strains we studied (E1 and E3) is constitutive, inducible by GlcNAc, and sensitive to feedback repression and to the 'glucose effect'. The mutant strain E3 differs from E1 in displaying a high level of constitutive chitinase activity (100-fold higher 
than in E1) and being more resistant to the repressor effect of GlcNAc. The sequence of events involved in induction of chitinase activity by insoluble chitin is not clearly understood. There is strong evidence supporting the role of constitutive chitinase activity in the induction phenomenon. Chitin is a large insoluble polymer and cannot enter the cell. The constitutive level of chitinase activity may be sufficient to initiate chitin degradation. The soluble products liberated could induce either the biosynthesis or activation of enzyme(s). The product of chitin degradation could act as either inducer or repressor according to its concentration in the medium. As a consequence, the production of enzyme depends on a delicate balance between induction and repression. In our case, the existence of a constitutive level of chitinase activity was demonstrated in the wild-type and the mutant strains. Moreover, mutant E3 had a high level of constitutive chitinase activity which allowed an early degradation of chitin and an early induction of chitinase activity, compared to the wild-type strain. Chitinase activity of the mutant strain was also less repressed by GlcNAc than that of the wild-type strain. Low transport of GlcNAc or poor metabolization of this molecule in the mutant could perhaps explain this result. We are currently investigating this. The high level of constitutive chitinase activity and high resistance to repressor effect of GlcNAc could explain the overproduction of chitinase activity by mutant E3.

In conclusion, we have isolated a mutant, $\mathrm{E} 3$, of $A$. album which is genetically stable and secretes high amounts of extracellular chitinase that is active on native chitin. This mutant is resistant to feedback repression and displays a high level of constitutive chitinase activity. A. album, which is a Cephalosporium-like fungus, can be easily grown in fermenters (G. Défago, personal communication). We consider this mutant to be a good candidate for testing the potential applications of chitinase.

We sincerely thank Dr P. Saindrenan and Dr D. Guest for critical reading of the manuscript.

This work was supported in part by grants from ANVAR (Agence Nationale de Valorisation de la Recherche) (France) and from Sanofi Elf Bio-Recherches (France).

\section{References}

Boller, T. (1986). Chitinase: a defense of higher plants against pathogens. In Chitin in Nature and Technology, pp. 223-231. Edited by K. Muzzarelli, C. Jeuniaux \& G. W. Gooday. New York: Plenum Press.

Cosio, I. G., Fisher, R. A. \& CARroad, P. A. (1982). Bioconversion of shellfish chitin waste: waste pretreatment, enzyme production, process design, and economic analysis. Journal of Food Science 47, 901-905.
Coudron, T. A., Kroha, M. J. \& IGoffo, C. M. (1984). Level of chitinase during development of three entomopathogenic fungi. Comparative Biochemistry and Physiology 79B, 339-348.

Fuchs, R. L., Mc Pherson, S. A. \& Drahos, D. J. (1986). Cloning a Serratia marcescens gene encoding chitinase. Applied Environmental Microbiology 51, 504-509.

Gooday, G. W. (1986). Chitinase activities in animals, fungi and bacteria. In Chitin in Nature and Technology, pp. 241-261. Edited by R. Muzzarelli, C. Jeuniaux \& G. W. Gooday. New York: Plenum Press.

HADWIGER, L. A., KeNDRA, D. F., FRISTENSKY, B. W. \& WAGONER, W (1986). Chitosan both activates genes in plants and inhibits RNA synthesis in fungi. In Chitin in Nature and Technology, pp. 209-215. Edited by R. Muzzarelli, C. Jeuniaux \& G. W. Gooday. New York: Plenum Press.

Jeuniaux, C. (1963). In Chitine et Chitinolyse, un Chapitre de la Biologie Moléculaire, p.181 Edited by C. Jeuniaux. Paris: Masson.

Jones, J. D. G., Grady, K., Suslov, T. V. \& BedBrooK, J. R. (1986). Isolation and characterization of genes encoding for two chitinase enzymes from Serratia marcescens. EMBO Journal 5, 467-474.

KeEN, N. T. \& YoshiKaWA, M. (1983). $\beta$-1 $\rightarrow$ 3-Endoglucanase from soybean releases elicitor-active carbohydrate from fungus cell walls. Plant Physiology 71, 460-465.

Lund, P., LeE, R. Y. \& Dunsmuir, P. (1989). Bacterial chitinase is modified and secreted in transgenic tobacco. Plant Physiology 91, $130-135$.

Manning, K. \& Wood, D. A. (1983). Production and regulation of extracellular endocellulase by Agaricus bisporus. Journal of General Microbiology 129, 1839-1847.

Molano, J., Duran, A. \& Cabib, E. (1977). A rapid and sensitive assay for chitinase using tritiated chitin. Analytical Biochemistry 83, 648-656.

Monreal, J. \& ReEse, E. T. (1969). The chitinase of Serratia marcescens. Canadian Journal of Microbiology 15, 689-696.

NeLsoN, N. (1944). A photometric adaptation of the Somogyi method for the determination of glucose. Journal of Biological Chemistry 153, 375-380.

Ordentlich, A., Elad, Y. \& Chet, I. (1987). Rhizosphere colonization by Serratia marcescens for the control of Sclerotium rolfsii. Soil Biology and Biochemistry 49, 747-751.

PIRT, S. L. (1971). The diffusion capsule, a novel device for the addition of a solute at a constant rate to a liquid medium. Biochemical Journal 121, 293-297.

REID, J. D. \& OGRYDZiAK, D. (1981). Chitinase-overproducing mutants of Serratia marcescens. Applied Environment Microbiology 41, 664-669.

Reissig, P. L., Strominger, J. L. \& Leloir, L. F. (1955). A modified colorimetric method for the estimation of $N$-acetylamino sugars. Journal of Biological Chemistry 217, 959-966.

ROBERTS, R. L. \& CABIB, E. (1982). Serratia marcescens chitinase: onestep purification and use for the determination of chitin. Analytical Biochemistry 127, 402-412.

RoberTs, W. K. \& SelitrenNikofF, C. P. (1988). Plant and bacterial chitinases differ in antifungal activity. Journal of General Microbiology 134, 169-176.

Schlumbaum, A., Mauch, F., Vogeli, U. \& Boller, T. (1986). Plant chitinase are potent inhibitors of fungal growth. Nature, London 324, 365-367.

Shapira, R., Ordentlich, A., Chet, I. \& OpPenheim, A. B. (1989). Control of plant diseases by chitinase expressed from cloned DNA in Escherichia coli. Phytopathology 79, 1246-1249.

Skujins, J. J., Pogieter, H. J. \& AleXander, M. (1965). Dissolution of fungal walls by a streptomycete chitinase and glucanase. Archives of Biochemistry and Biophysics 111, 358-364.

SMITH, J. \& GrULA, E. A. (1983). Chitinase is an inducible enzyme in Beauveria bassiana. Journal of Invertebrate Pathology 42, 319-326.

SNEH, B. (1981). Use of rhizosphere chitinolytic bacteria for biological control. Phytopathologische Zeitschrift 100, 251-256.

Soto-GIL, R. W. \& ZYsKIND, J. W. (1984). Cloning of Vibrio harveyi chitinase and chitobiase genes in Escherichia coli. In Chitin, Chitosan and Related Enzymes, pp. 209-223. Edited by J. P. Zirakis. London: Academic Press. 
Srivastava, A. K., Defago, G. \& Boller, T. (1985). Secretion of chitinase by Aphanocladium album, a hyperparasite of wheat rust. Experientia 41, 1612-1613.

St Leger, R., Cooper, R. M. \& Charnley, A. K. (1986). Cuticledegrading enzymes of entomopathogenic fungi: regulation of production of chitinolytic enzyme. Journal of General Microbiology 132, 1509-1517.

TOM, R. A. \& CARROAD, P. A. (1981). Effect of reaction conditions on hydrolysis of chitin by Serratia marcescens QM B1466 chitinase. Journal of Food Scinece 49, 379-380.
Wortman, A. T., Somerville, C. C. \& Colwell, R. R. (1986). Chitinase determinants of Vibrio vulnificus: gene cloning and application of a chitinase probe. Applied Environmental Microbiology 52, 142-145.

Young, M. E., Bell, R. L. \& Carroad, P. A. (1985a). Kinetics of chitinase production. I. Chitin hydrolysis. Biotechnology and Bioengineering 27, 769-775.

Young, M. E., Bell, R. L. \& Carroad, P. A. (1985b). Kinetics of chitinase production. II. Relationship between bacterial growth, chitin hydrolysis and enzyme synthesis. Biotechnology and Bioengineering 27, 776-780. 